- $\quad$ Research in Language 2007, vol. 5

DOI: 10.2478/v10015-007-0009-z

\author{
Andrzej Pawelec* \\ Jagiellonian University of Kraków
}

\title{
A NOTE ON ICONICITY AND MOTIVATION OF EXPRESSION ${ }^{1}$
}

\begin{abstract}
:
While iconic effects can be detected at all levels of linguistic analysis, according to the standard position they have little, if any, relevance for the system of language. I would like to show that iconicity seems marginal only in static approaches. Motivation of form is central whenever a new way of expressing things is looked for. Once we see that language is about finding new means of expression, the obvious question to ask is what makes these means suitable: why they are accepted as satisfactory 'vehicles' of meaning. From this point of view, the issue of iconicity - correspondence of form and meaning - turns out to be an instance of a more general phenomenon: adequacy of symbols for novel tasks. The interactive theory of metaphor will be presented to substantiate the claim that conventional forms and meanings can be viewed as a reservoir of motives for expressive purposes.
\end{abstract}

Keywords: Peirce, icons, iconicity, motivation in language, metaphor.

\section{Introduction}

The position presented in this paper may seem paradoxical. On the one hand, I believe that the extent of motivation in language is much greater than it is assumed in the structuralist paradigm. On the other hand, I do not think that 'iconicity' - based on Peirce's typology of signs - plays an important role in language. My aim, then, is to praise motivation, while being iconoclastic. Let me add that my perspective is that of a philosopher interested in language as a primarily social and expressive phenomenon.

The question of motivation in language may be formulated in the following way: is the relation between linguistic form and meaning arbitrary or is

* Author's address: Andrzej Pawelec, 32-003 Podłęże 552; e-mail: apa@vela.filg.uj.edu.pl

1 The first version of this paper was presented during the Fifth International Symposium "Iconicity in Language and Literature", Kraków, 17-20 March 2005. 
it rooted in the perception of the world? In the historical debate that serves as our point of departure Karl Bühler notices that language is a field phenomenon; words (as different from names) have meanings only in fields (deictic and syntactic). This is a very important discovery of the structuralists: there are no atomic meanings; a single meaning appears only as a choice out of an ideal matrix of options, defined by differences. Consequently, Lautmalerei (die lautmalende Sprache) - painting with words - could have been important only in the genesis of language, when a proper 'representing field' (Darstellungsfeld) was not yet established; now it is a fringe phenomenon used for expressive purposes (cf. Bühler 1934/1965: 195ff).

Bühler attacks the position of Heinz Werner (cf. Werner, Kaplan 1963), who claims that language is physiognomic, that it reflects the way things appear to us. Werner postulates another field - 'semantic' - rooted in our direct apprehension of the world and offers a wealth of psychological evidence to substantiate the view that the form/meaning relationship is natural, embodied: the form of words reflects our grasp of their denotations, since both words and perceptions of entities were shaped in one and the same process of original 'expression'. Bühler dismisses Werner's approach, labeling it 'Die Sprache im Dienste eines (im Laboratorium hochgezüchteten) Ausdruckswillens' (Bühler 1965: 196). Can we tell who is right?

At this point, we can observe that these positions need not clash, if we remember that a system of differences establishes only the 'value' of a linguistic sign - its potential for signifying. To arrive at a specific meaning of a linguistic form we certainly need the contribution of a particular context, which may involve our perception of things as reflected in language.

\section{Peirce's typology of signs and iconicity}

Let us try to elucidate the idea that language 'reflects' our perception of the world. We shall start with Peirce's classification of signs to pinpoint its limitations in our context and look for remedies (my presentation is based on Nöth 1995). Peirce divides signs into three categories: icons, indexes and symbols, and further subdivides icons into: images, diagrams, metaphors. Since this classification is widely known, we shall only observe that it is based on the following criterion: what allows one thing (sign vehicle) to signify or stand for another (its object)? In the case of icons it is a feature of this thing, shared with the other one; in the case of indexes it is a natural 
relation joining the two (e.g. cause-effect); in the case of symbols the semiotic link is rooted in convention. Strictly speaking, all language is symbolic, but there remains the question whether some linguistic sign vehicles have a "natural' component - iconic or indexical.

Let us start with the first group of icons, namely images. The most obvious case is onomatopoeia: a sign vehicle shares some features with its object (e.g. 'cuckoo' imitates the sound produced by the bird). We may notice that the scope for such a 'direct' imitation in language (originally, only spoken) had to be limited to the domain of sounds - one could not vocally 'paint' mute entities. What is more important, however, is the lack of correspondence between the act of imitation and meaning: the sound produced by humans (sign vehicle) does not signify the call found in nature but rather the author of such calls. This, of course, is recognized by Peirce: in his classification all language is conventional - instituted by law. Mere imitation of sounds does not generate the right meanings.

What, then, is the role of 'imaginal iconicity', or a direct similarity (a shared quality) between a sign vehicle and its object? It is assumed that such a similarity 'motivates' the conventional meaning. The question of $\mathrm{h}$ o $\mathrm{w}$ or $\mathrm{w} \mathrm{h} \mathrm{y}$ this happens is rarely raised. The case of the cuckoo - a bird rarely seen and most conspicuous by its call - reveals, I believe, that the sign vehicle imitates the feature of the object which seems best suited for its identification. If this is so, we may conclude that motivation in language is not primarily about similarity but about its expressive potential (does it help to identify the right intention?). Let us notice that other sounds which are commonly associated with their producers, e.g. 'bow-wow', 'oinkoink', are $\mathrm{n}$ o t used as names, because they do not seem to reveal the nature of these animals ('hound', however, seemed proper - indexically linking 'dogs' with 'hunting'). Again, these remarks are not meant as a criticism of Peirce's classification or his further goals (that would require an analysis of his writings). I merely point out that, contrary to popular presentations of iconicity, the contextual expressive potential of a sound is more important than an objective similarity (one could find many such similarities). In short, imaginal iconicity is about striking similarities.

In Peirce's classification of icons there are two further cases: diagrams and metaphors. 'Diagrammatic iconicity' in language is a correspondence between relations of sign vehicles and their objects, e.g. a longer vehicle may mean a bigger object or more of it (reduplication used as the plural form in some languages). The typical example, however, is when a sequence of words, phrases or clauses reflects some order in reality. What we see here is that previously established sign vehicles are modified or linked for 
expressive purposes. How do such phenomena 'motivate' meaning? Apparently, some structural features of expression (formal departures from convention, order of statement) are viewed as sufficiently suggestive of the intention to be expressed. Incidentally, we may notice that this mechanism ('double analogy' in the domain of sign vehicles and meanings) was described by Humboldt in his 'energetic' definition of language (cf. Humboldt 1999).

To give an example, in Polish 'the sequence of tenses' is not obligatory, so we can report past events using either past or present forms of the verb in the embedded clause. The following sentences are completely synonymous on the 'objective' level:

(1) Widziat, ze droga byta pusta.

He saw that the road was empty.

(2) Widziat, ze droga jest pusta.

He saw that the road is empty.

However, the present form suggests a change of perspective: the event is now presented from the point of view of the participant rather than the omniscient narrator (cf. Tabakowska 1993). If we want to treat this example as a case of diagrammatic iconicity, we must interpret 'form' liberally: not as the shape of sign vehicles but rather as their grammatical force. Then we can say that the relation between past and present forms reflects, is analogous to the relation between the distance to the scene of the participant and the narrator (the former is closer to it than the latter).

I hope that we begin to see better now that a given meaning is not 'out there', ready to be picked with the right tool (similarity or analogy between sign vehicles and their objects). A meaning may 'appear' only if we already look for it or are attuned to it, and we search for the most evocative way of grasping it. The mere presence of some objective relation is never enough, since anything can be connected with anything else via an infinite number of objective relations.

Peirce's 'metaphoric' symbols are called 'iconic metasigns' (Nöth 1995: $123,133)$. Let us try to explain this notion with a worn-out example:

Sally is a block of ice.

This metaphor is taken to mean that Sally is unresponsive to somebody's advances. The metaphorical expression 'a block of ice' is an 'iconic metasign' because it is supposed to signify by reference to other signs; more spe- 
cifically, by reference to the similarity between their objects. In this case we have the literal meaning of 'a block of ice' (called the 'vehicle' of the metaphor) and something that could serve as a conventional description of Sally's behavior (called the 'tenor' of the metaphor), e.g. 'frigid'. Perceived similarity between blocks of ice and frigid persons motivates this metaphor - makes it possible to describe Sally in this particular way. The connection between 'ice' and 'sexual frigidity' is so conventional, however, that this metaphor is dead.

In order to see how motivation works, we need an extended example of a live metaphor (my analysis owes much to Perrin 1987). Let us have a look at a passage taken from Thoreau's Walden:

Early in the morning, while all things are crisp with frost, men come with fishing reels and slender lunch, and let down their fine lines through the snowy field to take pickerel and perch; wild men, who instinctively follow other fashions and trust other authorities than their townsmen, and by their goings and comings stitch towns together in parts where else they would be ripped (Thoreau 1961: 189).

Wild men - we are told - 'stitch' towns together (the 'vehicle'). The tenor of this metaphor is perhaps 'they join towns by their footprints'. It is easy to see the similarity between the vehicle and the tenor (the common 'schema' or 'the ground' of the metaphor): the imprints left in snow resemble stitches and 'goings and comings' are as regular as stitching. Does this similarity motivate the meaning of the metaphor? What is its meaning? The physical movements of anglers - who do not really belong in towns - is viewed as an important unifying activity. One can speculate that Thoreau perceives the 'wild men' as Nature's envoys who inadvertently restitute its unity partly destroyed by towns. In order to understand this metaphor (if such is its meaning), we must adopt an unusual perspective on things-unusual, that is, for town-dwellers but quite attractive to someone like Thoreau. We must view towns as causing rifts in Nature, and anglers as Nature's response to this threat.

Let us try to describe the mental work necessary to produce and understand a creative metaphor (that is, a metaphor expressing a perspective sufficiently different from conventional ones). In the case presented above, Thoreau struggles to formulate the role of anglers in nature. First, he calls them 'wild men'; in a conventional context this phrase would suggest 'lack of civility' or 'lack of restraint' but here it merely means that they belong to nature. This interpretation is confirmed by the clause: "who instinctively follow other fashions', which means, perhaps, that the anglers have different habits than town-dwellers (and not that they are dressed differently). The sequence of 
words: 'wild', 'instinctively' and 'authorities' suggests that the anglers, in a way, are sent on an errand, that they heed the call of someone much more powerful. Only in this context does the word 'stitch' makes good sense. From the conventional perspective, 'wild men' cannot be expected to 'stitch' - to perform an action requiring patience and conscientiousness. Thoreau may view them as instruments: it is Nature who guides their movements and who is responsible for 'stitching'.

The author of the metaphor starts with a vivid experience of the tenor: in his mind's eye he perceives the movements of the anglers from an unusual perspective (perhaps, it is a bird's eye view encompassing a huge expanse of land; the physical perspective, however, is secondary to the perception of the anglers as being 'on a rescue mission'). To express this vision he needs a good vehicle which would suggest both the anglers' action and their function in Nature's order of things. The use of the word 'stitch' is, I believe, contingent. It is perhaps motivated by the fact that the semantic field of clothing and fabric has been activated ('fashions'); it is certainly motivated by the bird's eye view of the winter scene (which provides the ground, the common schema). As long, however, as this scene is not crystallized into a particular image, the original intention can find other vehicles. What is more, it often happens that in a text one metaphor is replaced by another one when the speaker realizes that his first choice has possible consequences which clash with his perspective. To use a simile, one could say that the speaker is like a cloud which is ready to snow but requires some specks of dust to crystallize - the shape of a particular snowflake is contingent on its nucleus of crystallization.

As a hearer one has no access to the lived experience of the speaker. One can only try to piece together the clues provided. In this case one must first solve the 'riddle' of the metaphor: why 'stitch' was used? This is easy when the tenor is tangible - when the context makes it sufficiently clear what the speaker talks about. Then the ground of the metaphor (the common schema of vehicle and tenor) is easy to find. The job of understanding the metaphor is still to be done: we must try to understand the situation from a new perspective.

When we deal with creative metaphors aiming at a total change of perspective (like Heidegger's 'Man is the shepherd of Being'), then neither the vehicle, nor the tenor are tangible enough. Of course, we realize that man's attitude to Being is supposed to be - in some respects - similar to a shepherd's attitude to his flock. But we do not know what it is about shepherding that is relevant and which human actions count as 'guarding of Being' (see Heidegger's explanations, e.g. 1975: 184-185).

The issue discussed above was perceptively presented by the Romantics. In a famous passage in his A Defence of Poetry Shelley says: 
Language is vitally metaphorical; that is, it marks the before unapprehended relations of things and perpetuates their apprehension, until words, which represent them, become, through time, signs for portions or classes of thought instead of pictures of integral thoughts: and then, if no new poets should arise to create afresh the associations which have been thus disorganized, language will be dead to all the nobler purposes of human intercourse", (quoted after Richards 1965: 90-91).

This breathtaking statement merits a longer discussion, but in the present context it is enough to notice that the task of revelation - of grasping new objects of thought - requires some 'twisting' of the available, conventional means of expression to direct thinking down a new lane. Such creative metaphors are not just based on similarities or analogies - on a 'transfer' of schemas into a new domain (to use Lakoff's terms). They are rather like springboards, they require a leap of imagination.

\section{Conclusion}

In all cases of linguistic icons - conventional signs motivated by similarity - their meanings are not motivated by similarity. To repeat, this does not contradict Peirce's classification; it merely shows that he did not focus on the connection between similarity and conventional meaning. What could we say about this connection? We could say, perhaps, that language users will grab anything available in the common, intersubjective space that could be used for expressive purposes. In tribal life, sounds produced by different animals are already a common currency (especially when imitated in rituals). Thus, they can serve as a perfect material for everyday communication: not just for naming or evoking some beings (the case of 'cuckoo') but for expressing anything of concern (we can imagine, for instance, that the sounds produced by escaping rabbits could be used to express 'fear' or 'cowardice' or 'speed'). This expression is no doubt 'physiognomic': names reflect the features by which an entity 'manifests' itself to a community.

Once the business of expression is started, however, there accumulates a fund of conventional signs - a new common currency - which will be used for novel purposes. Relations of form (between sign vehicles or grammatical variants) as well as transfers of symbols to unusual contexts may be suggestive of new meanings. The signs - by virtue of these relations - steer attention; their meaning, though, is 'inferred' or 'intuited' by taking stock of the whole situation.

Is language arbitrary? Language, pace Bühler, is basically expressive - suited in some ways to 'carry' the intended meaning. The idea of 'convention' as based on a prior agreement (language as a code) makes no sense. 
All novel, unconventional meanings must be motivated - their vehicles must be sufficiently 'expressive'. But 'sufficiently' is always contextual, contingent. We may agree that the meaning of 'cuckoo' (and its variants) is universal (if this is the case) because of its natural expressive value, but very little of nature is so powerfully expressive (which severely limits the range of onomatopoeia in conventional usage). The initial contingency is historically strengthened and used for novel purposes. This is why Werner's search for 'word physiognomies' seems so weird ('cooked up in the lab', to paraphrase Bühler). Words can signify not because they are linked to some basic level of experience (if there is such a thing), but because they are embedded in historical 'apprehensions' of the world. This process may be likened to the Darwinian 'descent of species' with one crucial difference: languages are adapted not to the changing environment but to the life of the community which they help to shape. It is not a cause-effect process as in nature, but rather an imaginative, creative process of seeing the world - or better still, interacting with the world - in novel ways.

'Iconicity', I would like to submit, captures only a fairly superficial aspect of the process of expression. It is also misleading, if we view it in the Peircean framework: as that part of convention which is based on 'objective' similarities or analogies. This is so because all 'objective' features had first to be made manifest in the process of expression. More crucially, in this process a similarity between form and meaning is only a prompt, an incentive to find 'the integral thought'.

To conclude these rambling observations, my discussion of iconicity and motivation in language does not constitute an argument. It is offered here only as a reminder that a perspective on this subject is available which is not only starkly opposed to current 'naturalistic' approaches, but may also (in more rigorous hands) turn out to be fruitful.

\section{References}

B üh le r, K. 1965. Sprachtheorie. Die Darstellungsfunktion der Sprache. Stuttgart: Gustav Fischer Verlag.

He i degger, M. 1975. Poetry, Language, Thought. New York: Harper.

Humboldt, von W. 1999. On Language. Cambridge: Cambridge University Press.

Nöt h, W. 1995. Handbook of Semiotics. Bloomington: Indiana University Press.

Perri n, S. G. 1987. "Metaphorical Revelations". Metaphor and Symbolic Activity 2(4), 251-280.

Richards, I. A. 1965. The Philosophy of Rhetoric. New York: Oxford UP.

Tabakowska, E. 1993. Cognitive Linguistics and Poetics of Translation. Tübingen: Gunter Narr.

Th ore a u, H. D. 1961. Walden. New York: Signet.

Werner, H., B. Kaplan 1963. Symbol Formation. New York: J. Wiley \& Sons. 